\title{
Myenteric Nerve Plexus
}

National Cancer Institute

\section{Source}

National Cancer Institute. Myenteric Nerve Plexus. NCI Thesaurus. Code C52748.

A network of nerves and part of the enteric nervous system located between the layers

of the muscularis externa in the gastrointestinal tract that functions to regulate motility 